\section{Physique Related Perceptions and Biological Correlates of Eating Disorder Risk among Female Collegiate Equestrians}

Eva V. Monsma ${ }^{1 *}$, Jennifer L. Gay ${ }^{2}$ and Toni M. Torres-McGehee ${ }^{3}$

\begin{abstract}
This study examined physique-related and biological predictors of eating disorder risk in a sample of 138 female collegiate equestrian athletes among whom the point prevalence risk was $42 \%$. English $(n=91)$ and Western $(n=47)$ riders reported age ( $M=19.88$ years), height, weight, age at menarche, menstrual regularity and completed the Eating Attitudes Test-26 (EAT-26), Social Physique Anxiety Scale (SPAS), and clothing-based items associated with the Stunkard Silhouette Scale. Mean comparisons indicated homogeneity between riding discipline in all variables. Correlation analyses showed riders who perceived themselves as larger (Body Image>BMI) had significantly higher SPAS and EAT26 scores. BMI, body image dissatisfaction in daily clothing, and SPA all contributed significant, unique variation in EAT-26 scores; Body image dissatisfaction and SPA contributed more than BMI. Implications of these findings in a sample with particularly low BMI scores suggest practitioners should focus on self-perception management strategies. Researchers are encouraged to continue examining body image distortion relationship in samples with a wider range of BMI.
\end{abstract}

\section{Keywords}

Eating disorders; Body Image (BI); Female athletes

\section{Introduction}

Sport-specific features of certain sports are implicated as perpetuating eating disorder risk and this is especially prominent among female athletes competing in aesthetic sports [1]. Form-fitting uniforms and where there is a subjective evaluation component to determining performance success characterize aesthetic sports [2]. Contextual mechanisms common within this sport classification involve public weigh-ins, comments about physique, costume features and subjective evaluation by judges magnify the typical pressures associated with pursuing success in sport especially if physical characteristics do not meet sport demands. Biocultural and contextual approaches to understanding human development frame this study because they postulate links among variables reflecting sport-specific task demands, environmental pressures, along with individual psychological and biological variables as they

*Corresponding author: Eva V. Monsma, Department of Physical Education and Athletic Training, 218 Blatt PE Center, University of South Carolina, USA Tel: 803-777-1386; Fax: 803-777-1386; E-mail: eavadocz@mailbox.sc.edu

Received: November 10, 2012 Accepted: February 15, 2013 Published: February 18, 2013 relate to behaviors such as disordered eating [3]. For example, early specialization is a common feature of many aesthetic sports where sport skill development coincides with critical periods of growth and maturation. Normal increases in physical size, weight and physique changes are met with concerns about physique which are known correlates of disordered eating risk [4] and generally increase with age with spikes between 10 and 11 and 13 and 14 among physically active adolescents [5]. Physical changes during this time are considered liabilities for success particularly in sports favoring leanness and linearity as ideal presentation components entwined with technical skill evaluation. According to Ziegler et al. [6], negative self-perceptions tied to physique manifest as anxiety and are linked to unhealthy dietary outcomes associated with caloric restriction and over-training. Among elite Norwegian female athletes, eating disorder symptoms are documented to typically develop between the ages of 14 and 25 years where 15\% report subclinical disordered eating symptoms (anorexia nervosa, bulimia nervosa, anorexia athletica, and eating disorders not otherwise specified [1]).

Studies of eating disorder risk factors including those among athletes include both biological (e.g., onset of menarche) and psychosocial (e.g., body image dissatisfaction) variables. Researchers have long advocated the concurrent consideration of biological characteristics such as menstrual regularity and maturational timing along with psychological characteristics $[7,8]$. They argue that causal pathways concurrently linking anthropometric and psychological indicators to disordered eating have yet to be established despite assertions that disordered eating is tied to critical periods of growth and development where both biological and psychological factors change in tandem [9]. What is not known is how each of these variables contributes uniquely to eating disorders [10].

Research designs that consider biological indicators of maturational timing concurrently with psychological characteristics is relatively new in the sport science literature perhaps because of misguided or biased ideas concerning maturation and the role of sport training. Evidence of late maturation is typically explained by suggestions that intensive training during the adolescent growth spurt delays achievement of biological maturity, particularly in females [11]. However, this still common assertion must be balanced with an understanding that menarcheal timing is heritable [12-14] with attention to four important points: 1) such generalizations can only be evaluated on the basis of longitudinal data; 2 ) there are between- and within-sport familial resemblances in menarcheal timing as indicated by significant mother-daughter correlations in age at menarche; 3) physical characteristics vary systematically by maturational timing and similarly by sport (i.e., leanness, relative leg length and linearity among late maturers are common across aesthetic sports which favor late maturation); and 4) there is a relative lack of early maturers in aesthetic sport samples [12]. Under these assumptions, the present study aims to elucidate predictors of disordered eating risk by considering relationships between biological and psychological variables and as they may vary across sport context (i.e., riding discipline). Age at menarche, BMI and menstrual regularity are the biological variables that will be addressed. 
Body image (BI) dissatisfaction is a well-documented psychological determinant of disordered eating across populations [15] particularly in women and is typically measured as a difference score between perceived and ideal images using Stunkard silhouettes [16]; higher positive difference scores indicate a desire to be smaller while negative difference scores indicate wanting to be larger. Individuals with higher BMI tend to report higher dissatisfaction using this scale. Interestingly, Hausenblas and Downs [17] reported more positive BI among athletes and no significant differences in effect size of BI disturbance between aesthetic and non-aesthetic sport athletes. This is in contrast to evidence that aesthetic sport athletes report greater self-presentation concerns [18-20]. In addition to unaccounted biological differences in many sport psychology studies, the mixed evidence regarding aesthetic and non-aesthetic athletes may lie within a feature of the sport. For example, track is considered an aesthetic sport even though performance does not involve subjective evaluation. However, recent findings show the physique of track athletes varies by distance and event type, as does BI dissatisfaction [21].

BI studies have also revealed that dissatisfaction is positively correlated with excessive exercise [22] and anxiety among athletes $[10,18]$. Social physique anxiety (SPA), anxiety experienced when presenting one's body in front of others, is another variables of concern, is presumed to develop during adolescence [23] and is one of the most salient psychological predictors of eating disorders among aesthetic sport athletes [18,20]. SPA is different from BI dissatisfaction because it involves an affective component contingent on presentation contexts whereas BI dissatisfaction involves general physique, within-self comparisons. Positive correlations between SPA and BI dissatisfaction are evident in the eating disorder literature [4] with no known indication of multicolinearity indicating SPA and $\mathrm{BI}$ dissatisfaction are separate yet unique constructs. Currently it is unknown whether BI dissatisfaction or SPA relate to biological variables and if these collectively contribute to disordered eating among equestrian competitors.

To date, the only known study to consider subclinical eating disorder risk in the collegiate equestrian population found an overall point prevalence risk of $42 \%$ among 138 participants 18 to 25 years, $38.5 \%$ among English and $48.9 \%$ among Western riding competitors [24]. The rate for the total sample is identical to an earlier study where Sundgot-Borgen and Torstveit [1] also estimated the subclinical eating disorder prevalence rate to be $42 \%$ among a heterogeneous sample of aesthetic sport athletes inclusive of this sport. That eating disorder prevalence was somewhat higher among Western riders, albeit not significantly, was attributed to the aesthetic characteristics of competitive uniform worn by riders and their judging specifications; Western riders wear tighter fitting jeans, choose increasingly flamboyant shirts to gain a competitive advantage in performance scores and endure judging focused more on how the rider controls the horse with her body than the more technical and demure English riders.

Although nearly half of the Western riders were at risk, prevalence was not significantly different compared to English riders [24]. Given the high prevalence rate for the total sample, examining possible correlates of disordered eating within each discipline was considered important for informing interventionists so we stratified the sample by riding discipline; this design strategy would help elucidate possible differences in biological and psychological variables that may be particularly linked to uniform and judging practices. We also continued our focus on these elite level competitors because of our interests in determining if relationships between biological and psychological variables existed among prototypical equestrians. Discovering possible discipline specific psychological and biological factors and if they coalesce at one of the highest levels of equestrian competition (i.e., Division I collegiate) is not only important to inform training practices at earlier training levels, but also for informing practitioners about possible intervention targets. Therefore the purpose of this study was to identify the most salient risk factors of disordered eating among collegiate equestrian athletes in both Western and English style riding, taking into consideration BI disturbance, SPA, riding context (Western vs. English), and maturation.

The relatively high eating disorder risk prevalence, especially among Western riders (49\%) albeit not significant than English riders (39\%), warrants examining possible determinants linked to physique and uniforms [24] and others concerning biological characteristics such as the timing of puberty [19] and menstrual irregularity [25] which have been implicated in the development of negative physiquerelated perceptions and behaviors. The current study addresses a gap in the evidence by accounting for anthropometric, maturational and contextual variables when considering BI dissatisfaction and distortion among the understudied population of equestrian athletes. Negative physique-related perceptions were expected to be prominent among Western riders given the higher prevalence of eating disorder risk in this group [24]. A combination of biological and physiquerelated variables is also expected to explain disordered eating risk in this sample.

\section{Methodology \\ Participants}

Participants were 138 female NCAA Division I varsity equestrian athletes 18 to 25 years of age $(M=19.88+1.29$ years) who competed in English $(\mathrm{n}=91)$ or Western $(\mathrm{n}=47)$ disciplines. The prevalence of eating disorder risk (42\%), body image disturbance and pathogenic behaviors across discipline are reported in Torres-McGehee et al. [24].

\section{Procedures}

Upon securing human subjects approval, all of the eighteen Division I varsity equestrian coaches were contacted for permission to solicit athlete participation. Coaches from seven institutions with equestrian teams $(38.8 \%)$ granted permission yielding a total of 211 athletes who were emailed a request to participate in the study, 138 consented (response rate $=65.4 \%$ ) and were sent a SurveyMonkey. com link to the survey. Every 10 days after the initial notification, a reminder email was sent to non-respondents to complete the survey. The survey was open for a total of 30 days during the peak competitive season.

\section{Measures}

Riding context, demographic and anthropometric data: Participants completed questions indicating: age, riding discipline, number of years riding, current height and weight.

Menstrual status questionnaire: Questions about age at menarche, menstrual cycle frequency and variability, menstrual dysfunction, and birth control use were completed by the participants 
[26]. In addition to age at menarche, recalled to the nearest half year, irregular periods were assessed by asking participants to self-report if they ever had irregular periods (Yes/No) such as not having a cycle every 21-35 days.

Body image dissatisfaction and distortion: BI was assessed using the sex-specific Stunkard Figural Stimuli [16]. Participants were presented with the nine silhouettes ranging from underweight to morbidly obese. Respondents were asked to select a silhouette that best represented their answer to the following questions: (a) which silhouette best represented your appearance in normal daily clothing (e.g., what you wear to school)?, (b) which silhouette best represented how you would prefer to appear in your normal daily clothing?, (c) which silhouette best represented your appearance in performance/ competition uniform?, and (d) which silhouette best represented how you would prefer to appear in your performance/competition uniform? BI dissatisfaction was measured as perceived, less ideal body image separately for daily clothing and uniforms. Positive values indicate that a participant has a smaller ideal body image, and negative values indicate a larger ideal BI.

BI distortion was also measured. Compared to BI dissatisfaction which is derived from two perception-based measures, BI distortion involves subtracting perceived BI from the Stunkard score representing the participant's BMI. Stunkard Figural Stimuli, Bulik et al. [27] sampled more than 16,000 participants who were identical twins, screened for BMI similarity, to systematically establish BMI values associated with each of the nine images on the rating scale; twins rated the other's physique using the Stunkard scale and images were then associated with the twins' BMI. Average BMIs associated with each anchor for women ages 18 to 30 , the age range of the participants in the present study, are as follows: 18-30, the age group inclusive of study participants such that silhouette $1=17.8$ silhouette; $2=18.8$; silhouette; $3=20.3$; silhouette $4=22.6$; silhouette $5=26.4$; silhouette $6=31.3$; silhouette $7=36.7$; silhouette; $8=40.8$; silhouette $9=44.1$. However, it is not possible to accurately capture the magnitude of BI distortion (i.e., participant BMI-perceived silhouette) [28] by simply subtracting a respondent's BMI from the BMI value associated with a selected silhouette; even with BMIs established to reflect the silhouette anchors, the scale is ordinal and precludes all BMI values that would exist between each anchor. Thus, the participant BMI's were transformed to Stunkard silhouette scores. Similar to BI dissatisfaction, positive values indicate that the participant sees herself as larger than actual BMI and negative values point to seeing herself as smaller.

Peterson et al. [29] used these BMI-based silhouettes, finding them valid for examining BI dissatisfaction (perceived BI- ideal $\mathrm{BI})$. The correlations reported by Peterson et al. [30] between BMI and perceived BI $(\mathrm{r}=0.85, \mathrm{p}<0.0001)$, and $\mathrm{BMI}$ and ideal $\mathrm{BI}(\mathrm{r}=0.82$, $\mathrm{p}<0.0001)$ indicate construct validity. While the Stunkard Figural Stimuli have some methodological limitations [31], the rating scale allows for direct comparison with actual BMI which is not possible using scales with Likert-type response formats. Furthermore, they were the most amenable option for administration via the online survey.

Social Physique Anxiety Scale (SPAS): The 9-item SPAS [32] assesses anxiety and individual experiences in the context of physique evaluation. The response format is a five-point Likert scale anchored by 'not at all' (1) and 'extremely' (5). Internal consistencies previously reported range from 0.90 to 0.93 among like participants [4]. In the present sample, the Cronbach [33] alpha coefficients was acceptable for the SPAS $(\alpha=0.79)$.

Eating disorder risk: The Eating Attitudes Test (EAT-26) [34] was administered to screen for eating disorder characteristics and behaviors. Although not diagnostic, the EAT-26 is commonly used as a screening tool to identify early characteristics and behaviors indicating the potential presence of an eating disorder. It includes three subscales: Dieting, Bulimia, and Oral Control which have shown adequate internal consistency $(\alpha=0.79)$ among young adult females [34]. In the present sample the internal consistencies for each scale were $0.90,0.79$ and 0.89 , respectively.

\section{Analysis}

Descriptive statistics were computed for discipline, age, selfreported BMI (weight in kilograms/height in meters ${ }^{2}$ ), age at menarche and menstrual irregularity, SPA, body dissatisfaction and distortion in both daily clothing and uniforms, and EAT-26 scores. Independent samples t-tests were used to assess potential differences by riding discipline in age at menarche, BMI, SPA, BI dissatisfaction and distortion, and EAT-26 scores. Differences in menstrual irregularity were tested using chi-square analysis. Given the evidence of strong associations among physical self-perception variables [28], Pearson's correlation coefficients were calculated for age at menarche, BMI, SPA, BI dissatisfaction and distortion, and EAT-26 scores.

A two-step process was used to address the aim of this study, to identify the most salient risk factors of disordered eating (i.e., EAT-26 scores) among equestrian athletes from anthropometric, maturation, self-perception, and riding context variables. First, a multiple linear regression was conducted to identify significant variables in the model predicting EAT-26 score and assess the variance inflation factor (VIF), a marker of co linearity (VIF $>10)$. The second step, a hierarchical regression analysis, was used to identify the variables contributing unique variation to EAT-26 scores. Variables that were significant in the multiple linear regressions were entered as covariates in Step 1 of the hierarchical regression. Remaining variables are entered stepwise into the model, and rotated through at the final step to assess the unique contribution of each to the dependent variable. A significant increase in $\mathrm{R}^{2}$ at step 3 suggests unique contribution. SPSS version 19 was used to conduct the analyses and all results are interpretable at $\alpha=0.05$.

\section{Results}

Eating disorder risk characteristics for the present sample revealed that fifty-eight participants $(42.0 \%)$ were classified as "at risk" for eating disorders based on pathogenic behaviors $(n=41)$, EAT-26 subscales $(n=6)$, or both pathogenic behaviors and EAT-26 subscales $(n=11)$. Supplemental questions for the total sample revealed $24.6 \%$ engaged in binge eating, $11.6 \%$ vomited to control weight or shape, $15.2 \%$ used laxatives, diet pills or diuretics to control weight, $3.6 \%$ reported having previously attempted or had thoughts of suicide, and $2.9 \%$ reported a previously having an eating disorder [24].

Sample characteristics are shown in Table 1. Mean BMI was 22.64 $( \pm 3.02$, range: $17.76-36.88,16 \%>25.0)$ which falls within the range for normal weight (BMI classification: World Health Organization, 2004). Average age at menarche was 13.00 ( \pm 1.31 , range: 9.00-17.00) which was slightly higher than the population for Caucasian females of European ancestry [3]: mean of $12.8 \pm 1.0$ years $(t(137)=1.37$, $p=0.08)$. Twenty eight percent $(n=38)$ of the participants reported 
Citation: Monsma EV, Gay JL, Torres-McGehee TM (2013) Physique Related Perceptions and Biological Correlates of Eating Disorder Risk among Female Collegiate Equestrians. $J$ Athl Enhancement 2:2.

irregular periods. Nearly two-thirds of the riders saw themselves as larger than their actual BMI in daily clothing (64.5\%) and uniform (63.8\%). However, the mean difference between perceived BI BMI (20) and actual BMI was within the difference between estimated BMI for figural stimuli [27].

Differences by riding discipline were assessed for menarcheal age and menstrual irregularity, BMI, SPA, BI dissatisfaction and distortion, as well as EAT-26 scores. No significant differences ( $p>0.05)$ were found between English and Western riding disciplines in these variables (Table 2).

Pearson correlation coefficients among age at menarche, BMI, SPA, BI and disordered eating risk variables are presented in Table 3. As expected there were strong, positive correlations between SPA and disordered eating $(\mathrm{r}=0.56-0.59)$ except for oral control $(\mathrm{r}=0.12)$. There

Table 1: Characteristics of Participating Equestrian Athletes $(\mathrm{N}=138)$

\begin{tabular}{|c|c|c|}
\hline & Variable & $\%$ or $M(S D)$ \\
\hline \multicolumn{3}{|l|}{ Discipline } \\
\hline & English & $65.9 \%$ \\
\hline & Western & $34.1 \%$ \\
\hline \multicolumn{3}{|l|}{ Year in School } \\
\hline & Freshman & $31.9 \%$ \\
\hline & Sophomore & $24.6 \%$ \\
\hline & Junior & $17.4 \%$ \\
\hline & Senior & $26.1 \%$ \\
\hline \multicolumn{3}{|l|}{ Years Riding } \\
\hline & $0-5$ & $10.9 \%$ \\
\hline & $5-10$ & $19.6 \%$ \\
\hline & $\geq 10$ & $69.6 \%$ \\
\hline \multicolumn{2}{|l|}{ Age } & $19.88(1.29)$ \\
\hline \multicolumn{2}{|l|}{ Age at menarche } & $13.00(1.31)$ \\
\hline \multicolumn{2}{|c|}{ Irregular Period, \% Yes } & $27.5 \%$ \\
\hline \multicolumn{2}{|l|}{ BMI } & $22.64(3.02)$ \\
\hline \multicolumn{3}{|c|}{ EAT-26 Risk Classification } \\
\hline & $\%$ At Risk & $42.0 \%$ \\
\hline \multicolumn{2}{|c|}{ EAT-26 Total item means } & $8.75(8.58)$ \\
\hline & Dieting & $5.46(6.24)$ \\
\hline & Bulimia & $1.78(2.29)$ \\
\hline & Oral Control & $1.51(1.96)$ \\
\hline \multicolumn{2}{|l|}{ SPA } & $2.83(.87)$ \\
\hline \multicolumn{3}{|c|}{ Body Image Dissatisfaction } \\
\hline & Daily Clothing & $1.09(0.95)$ \\
\hline & Uniform & $1.18(1.17)$ \\
\hline \multicolumn{3}{|c|}{ Body Image Distortion } \\
\hline & Daily Clothing & $-0.83(2.70)$ \\
\hline & Uniform & $-0.98(3.39)$ \\
\hline
\end{tabular}

Note: Body Image Dissatisfaction=perceived less ideal on figural rating scale. Range: $0.00-8.00$ for both daily clothing and uniform. Body Image Distortion=actual BMI less perceived image recoded to BMI based on Bulik et al. [27]. Daily Clothing Range: -20.14 to 4.91 . Uniform Range: -20.14 to 5.58 .
Table 2: Differences in Means for BMI, Menarche, and Body Image Variables by Riding Discipline.

\begin{tabular}{|c|c|c|c|c|}
\hline Variable & English $(n=91)$ & Western $(n=47)$ & $t$ & $P$ \\
\hline Age at menarche & 13.06 & 12.87 & 0.80 & 0.426 \\
\hline BMI & 22.55 & 22.80 & -0.42 & 0.673 \\
\hline SPA & 2.74 & 3.01 & -1.74 & 0.085 \\
\hline $\begin{array}{lll}\text { Dissatisfaction } & - & \text { Daily } \\
\text { Clothing } & & \\
\end{array}$ & 1.08 & 1.11 & -0.19 & 0.845 \\
\hline Dissatisfaction - Uniform & 1.22 & 1.11 & 0.54 & 0.590 \\
\hline Distortion - Daily Clothing & -0.85 & -0.80 & -0.11 & 0.916 \\
\hline Distortion - Uniform & -1.14 & -0.67 & -0.78 & 0.438 \\
\hline \multirow[t]{2}{*}{ EAT-26 } & 8.41 & 9.43 & -0.66 & 0.511 \\
\hline & & & $x^{2}$ & $P$ \\
\hline Menstrual Irregularity, \% & $28.6 \%$ & $25.5 \%$ & 0.144 & 0.705 \\
\hline
\end{tabular}

were also strong, positive associations between BI dissatisfaction for daily clothing and uniform, as well as for distortion for daily clothing and uniform. As BI distortion increased (riders seeing themselves as larger), BI dissatisfaction and SPA also increased. EAT-26 total scores as well as scores for dieting and bulimia were significantly correlated with BI distortion where athletes who perceived themselves to be larger than their actual BMI reported more disordered eating behaviors. Even stronger associations were seen for BI dissatisfaction than body image distortion with disordered eating.

Results of the multiple linear regression analyses are shown in Table 4. None of the variables had variance inflation factors above 10. However, the variance inflation factors for the uniform BI dissatisfaction and distortion were greater than 5.0. Given the strong correlation between daily clothing and uniform values for both BI dissatisfaction and distortion and the absence of significant contribution to EAT-26 scores, the uniform variables were removed to simplify the model. BMI, SPA and BI dissatisfaction were all significant predictor variables in the model explaining $42 \%$ of the variance in total EAT-26 scores.

Based on the results of the multiple linear regression model (Table 5), riding discipline, menstrual irregularity, age at menarche and BI distortion were entered into the model at Step 1. BMI, SPA and BI dissatisfaction were entered into Step 2, two at a time, with the third variable rotating in at Step 3. The $\mathrm{R}^{2}$ for the full model was $42 \%(\mathrm{P}<0.0001$; Table 5). BMI, body image dissatisfaction in daily clothing, and SPA all contributed significant unique variation to EAT-26 scores. However, BI dissatisfaction and SPA $\left(\Delta \mathrm{R}^{2}=9 \%\right.$ for both variables) contributed more variation than $\mathrm{BMI}\left(\Delta \mathrm{R}^{2}=2 \%\right)$.

\section{Discussion}

Female athletes in aesthetic sports, including equestrians, are at increased risk for eating disorders [1]. Previous findings by TorresMcGehee et al. [24] revealed the prevalence of disordered eating to be $42 \%$, in a relatively large proportion of the population of Division I collegiate riders (39\% of all teams in the United States). To extend the findings of Torres-McGehee et al. [24], the aim of this study was to examine relevant maturation, anthropometric, contextual and psychosocial factors associated with EAT-26 scores among these equestrian athletes. This study sought to examine disordered eating relationships involving SPA and $\mathrm{BI}$, and following suggestions of 
Table 3: Pearson Correlation Coefficients among age at menarche, BMI, SPA and Body Image Variables.

\begin{tabular}{|c|c|c|c|c|c|c|c|c|c|c|c|}
\hline & 1. & 2. & 3. & 4. & 5. & 6. & 7. & 8. & 9. & 10. & 11. \\
\hline 1. Age at menarche & -- & & & & & & & & & & \\
\hline 2. BMI & -0.15 & -- & & & & & & & & & \\
\hline 3. SPA & -0.01 & $0.43^{* * *}$ & -- & & & & & & & & \\
\hline 4. Dissatisfaction - Daily Clothing & 0.03 & $0.45^{\star \star *}$ & $0.59^{* * *}$ & -- & & & & & & & \\
\hline 5. Dissatisfaction - Uniform & 0.02 & $0.44^{* * *}$ & $0.63^{* * *}$ & $0.78^{* * *}$ & -- & & & & & & \\
\hline 6. Distortion - Daily Clothing & -0.07 & $0.21^{*}$ & $-0.24^{* *}$ & $-0.53^{* * *}$ & $-0.48^{* * *}$ & - & & & & & \\
\hline 7. Distortion - Uniform & -0.06 & $0.19^{*}$ & $-0.27^{* *}$ & $-0.40^{* * *}$ & $-0.62^{* * *}$ & $0.83^{* * *}$ & -- & & & & \\
\hline 8. EAT-26 Total & 0.05 & $0.19^{*}$ & $0.57^{\star \star *}$ & $0.59^{* * *}$ & $0.56^{* \star *}$ & $-0.32^{\star \star \star}$ & $-0.31^{* * *}$ & -- & & & \\
\hline 9. Dieting & 0.06 & $0.20^{*}$ & $0.54^{* * *}$ & $0.56^{\star \star *}$ & $0.53^{* \star *}$ & $-0.25^{\star *}$ & $-0.24^{* *}$ & $0.96^{* \star *}$ & -- & & \\
\hline 10. Bulimia & 0.02 & $0.21^{*}$ & $0.54^{* * *}$ & $0.58^{* * *}$ & $0.52^{* * *}$ & $-0.48^{* * *}$ & $-0.43^{* * *}$ & $0.78^{* * *}$ & $0.66^{* * *}$ & -- & \\
\hline 11. Oral Control & 0.04 & -0.04 & 0.12 & 0.13 & 0.15 & -0.07 & -0.11 & $0.43^{* \star *}$ & $0.23^{\star *}$ & 0.12 & -- \\
\hline
\end{tabular}

${ }^{*} \mathrm{p}<0.05 ;{ }^{* *} \mathrm{p}<0.01 ;{ }^{* * *} \mathrm{p}<0.001$

Table 4: Multiple Linear Regression Analysis Predicting EAT-26 Score.

\begin{tabular}{|l|l|l|l|}
\hline Variable & B & SE B & B \\
\hline Discipline (ref=English) & 0.04 & 1.20 & 0.00 \\
\hline Irregular Menstruation (ref = No) & 0.11 & 1.32 & 0.01 \\
\hline Age at menarche & 0.12 & 0.45 & 0.02 \\
\hline BMI & -0.60 & 0.27 & $-0.21^{*}$ \\
\hline SPA & 3.77 & 0.84 & $0.38^{* * *}$ \\
\hline Dissatisfaction - Daily Clothing & 4.55 & 1.01 & $0.50^{\text {** }}$ \\
\hline Distortion - Daily Clothing & 0.26 & 0.31 & 0.08 \\
\hline
\end{tabular}

\section{$\mathrm{R}^{2}{ }_{\text {Adj }}=0.417, \mathrm{~F}=14.99, \mathrm{P}<0.0001$.}

${ }^{*} \mathrm{P}<0.05$. ${ }^{* *} \mathrm{P}<0.0001$.

Table 5: Hierarchical Regression Analysis Identifying Unique Contributors to EAT-26 Score.

\begin{tabular}{|c|c|c|c|c|c|}
\hline Variable & B & SEB & B & $R^{2}$ & $\Delta R^{2}$ \\
\hline Step 1 & & & & $0.09^{* *}$ & \\
\hline Riding Discipline & 1.13 & 1.48 & 0.62 & & \\
\hline Menstrual Irregularity & 1.22 & 1.63 & 0.64 & & \\
\hline Age at Menarche & 0.13 & 0.55 & 020 & & \\
\hline Body Image Distortion & -0.99 & 0.26 & -0.31 & & \\
\hline \multicolumn{6}{|l|}{ Model 1} \\
\hline Step 2 & & & & $0.33^{* * *}$ & $0.25^{\star * *}$ \\
\hline BMI & 0.06 & 0.24 & 0.02 & & \\
\hline SPA & 5.07 & 0.84 & $0.51^{* * *}$ & & \\
\hline Step 3 & & & & $0.42^{* * *}$ & $0.09^{* * *}$ \\
\hline Daily Clothing Dissatisfaction & 4.55 & 1.01 & $0.50^{* * *}$ & & \\
\hline \multicolumn{6}{|l|}{ Model 2} \\
\hline Step 2 & & & & $0.33^{* * *}$ & $0.25^{\text {***}}$ \\
\hline BMI & -0.35 & 0.28 & -0.12 & & \\
\hline Daily Clothing Dissatisfaction & 6.12 & 1.02 & $0.68^{* * *}$ & & \\
\hline Step 3 & & & & $0.42^{* * *}$ & $0.09^{* * *}$ \\
\hline SPA & 3.77 & 0.84 & $0.38^{* * *}$ & & \\
\hline \multicolumn{6}{|l|}{ Model 3} \\
\hline Step 2 & & & & $0.40^{* * *}$ & $0.31^{* * *}$ \\
\hline SPA & 3.37 & 0.83 & 0.34 & & \\
\hline Daily Clothing Dissatisfaction & 3.33 & 0.86 & 0.37 & & \\
\hline Step 3 & & & & $0.42^{\star * *}$ & $0.02^{*}$ \\
\hline BMI & -0.60 & 0.27 & -0.21 & & \\
\hline
\end{tabular}

${ }^{*} \mathrm{P}<0.05$. ${ }^{* *} \mathrm{P}<0.01 .{ }^{* * *} \mathrm{P}<0.0001$.
Bonci et al. [26] and Dorn et al. [7], the study design considered biological and psychological variables concurrently. Following this unique research design and focusing on an elite level sample of equestrians, the majority with $>10$ years of experience, the most notable descriptive findings of this study support previous research highlighting the lack of within-sport variability at the elite level [12]; in this case for both physical and psychological variables.

Contrary to what was expected, no psychological scale differences were detected between English and Western riders. In theory, Western riders have more expectations in terms of body shape, size and movement than their English style counterparts and therefore might report greater SPA, BI dissatisfaction and distortion, as well as greater risk for disordered eating behaviors. However, the present finding is aligned with previous studies indicating little event-specific variability. Within track athletes, an aesthetic sport [2], elite male distance runners did not report increased anxiety, low self-esteem or more disordered eating behaviors compared to non-distance runners [35]. Similarly, a study of 412 elite track and field athletes revealed no significant differences between distance runners and sprinters [36]. One explanation for the homogeneity evident in these collective findings points to possible similarities in other variables such as biological characteristics which were not considered in previous studies. If psychological characteristics are tied to biological ones which show minimal variability at elite competitive levels [12] then within sport variation of psychological characteristics may also be minimal.

Interestingly, there was no relationship between psychological and maturation variables in this sample. In contrast with the recommendations by Dorn et al. [7], the physiological variable of age at menarche, was not significantly associated with eating disorder risk in our sample. Although there was evidence of later maturation in this sample (menarche $>12.8$ years), a non-significant one sample t-tests supported that this sample was not significantly later maturing than that of the population. Contrary to previous assertions that early menarche is associated with increased disordered eating risk $[8,37,38]$ and SPA [39], early maturation was not common in this aesthetic sport sample, and age at menarche did not correlate with any of the psychological variables in the study in this sample. Another possible explanation could be that time since menarche was greater than would be relevant to noticing associated changes in physical characteristics 
that typically occur during puberty. Menarche occurs on average at 12.8 ( \pm 1 years), about one year after the adolescent growth spurt where females experience between 5 and $25 \mathrm{~cm}$ increases in height and 7 and $25 \mathrm{~kg}$ increases in weight [40]. Women in this sample were well past puberty by about 5 to 12 years and were generally average maturing (age at menarche $=13.0+1.3$ years); it may be that the time since growth related events may have been long enough for the females to adjust to their physical changes. Subsequent studies should consider these variables among adolescent females who are in the midst of the peak height velocity growth period.

Regarding BI measures used in this study, the findings also call into question the utility of $\mathrm{BI}$ distortion as a separate construct. The moderate-to strong associations ( $\mathrm{r}=-0.40$ to -0.62$)$ with dissatisfaction combined with the lack of contribution to EAT-26 scores in the regression model suggests this may not be a relevant variable among elite equestrian athletes who are also homogeneous in physical characteristics as well as maturational timing. However, significant, positive BI distortion correlations with SPA and the EAT-26 scales do provide evidence of convergent validity and along with systematic, significant correlations with EAT-26 correlations, indicate the importance of $\mathrm{BI}$ for understanding the mechanisms of self-perceptions and eating disorders. The significant correlations between BMI and nearly all of the psychological variables indicated larger athletes perceived greater BI dissatisfaction, and reported higher SPA and EAT-26 scores which are consistent with previous findings [20]. While it is not surprising that larger athletes are increasingly dissatisfied with their BI, it is concerning that this was the case among a sample with fairly low BMI values (Total sample $\mathrm{BMI}=22.6 \pm 3.0)$ and that these perceptions were also accompanied by higher SPA and disordered eating risks. To date, few studies have examined BI distortion as the difference between perceived BMI and actual BMI using figural stimuli.

In a descriptive study, Christman et al. [28] found that women had larger difference scores than did men. In an earlier study, using a different methodology Casper et al. [41] calculated a ratio of the estimated and actual body width at various points in 79 anorexianervosa patients and found that they overestimated the width of their chest, waist and hips. Researchers are encouraged to continue investigating $\mathrm{BI}$ distortion with available instrumentation because BI distortion may be more prevalent in populations that vary more in physical size.

Despite these similarities across riding disciplines, the study certainly illuminates self-perception mechanisms involved in predicting disordered eating risk. In order to more accurately pinpoint eating disorder intervention targets, we considered whether BI dissatisfaction, distortion in daily clothing and in uniform along with SPA contributed unique variance to EAT-26 scores. Previous studies have examined relationships among BI related variables and disordered eating including among 180 undergraduate students where SPA, controlling for covariates, accounted for $34 \%$ of the variation in eating attitudes [42]; comparable to the $33 \%$ in this study when BI dissatisfaction is excluded. Similarly, BI variables were significant predictors of eating attitudes among 235 English boys and girls, accounting for a similar proportion (more than 40\%) of variation in disordered eating behaviors [22]. In the present sample, a combination of physical, contextual and psychological variables accounted for over $40 \%$ of disordered eating risk variability. More specifically, BI dissatisfaction in daily clothing explained as much variance as SPA (9\%). From a practical standpoint, SPA is experienced by equestrians in both daily clothing and perhaps slightly more so in uniform as evident from correlation magnitudes and regardless of physical size, those who experience either BI dissatisfaction or SPA report more disordered eating risk. Larger sample sizes and longitudinal designs will be important for establishing causal links among these variables. Subsequent studies should also consider other contextual factors such as pressures from coaches, peers and parents as they relate to $\mathrm{BI}$ variables and disordered eating risk.

It is also interesting to note that the valence of the correlations involving BMI switched in the presence of BI dissatisfaction in model 2 of the hierarchical regression. This can occur when the correlation is strong and is known as evidence of suppression [43]. However, examination of the correlation between BMI and body image dissatisfaction in this sample revealed a moderate correlation $(\mathrm{r}=0.45)$, with a shared variation of $20 \%$ [44]. BMI contributed a small amount of unique variation (2\%) to EAT-26 scores in this study. However, caution is warranted when interpreting results in future studies given the propensity for body image studies to include BMI.

Although this study highlights correlates of eating disorder risk among collegiate athletes, there are several limitations to consider. First, it is possible that there are characteristics on which participants and non-responders vary. Although nearly two-thirds of collegiate equestrian athletes surveyed participated in the study (65.4\%), a closer look at coaches' response rate $(39 \%)$ which was much lower albeit acceptable (>30\%), indicates over half of the coaches preferred not to provide access to their athletes. It is possible non-responding coaches engaged in questionable practices that were underlying assumptions of this study (e.g., public weigh-ins, pressure to lose weight). Second, it is unknown when equestrian participants began participation or specialized in equestrian, and if the timing coincided with maturation during adolescence. Subsequent investigations considering these biological relationships among younger participants who are in the midst of puberty could better delineate maturation and contextual influences. Third, another important aspect to consider is the temporal order of BI and SPA development, especially among adolescents who are in the midst of experiencing growth-related changes. Due to the cross-sectional nature of the study we are unable to determine whether the BI dissatisfaction and SPA is causing the disordered eating or if, at this point in a participant's athletic career, they may be co-occurring and the participants with disordered eating are the ones with the largest degree of dissatisfaction and SPA. Fourth, the actual BMIs used in our calculations were self-reported rather than measured. While objective measurements are ideal, research has shown that athletes, particularly in older adolescence [45] and those participating in aesthetic activities [46], are able to accurately selfreport their height and weight within the range of expected daily variations. Finally, the concept of BI distortion should be interpreted with caution because the recoded BMI anchors of the silhouettes are still ordinal measures whereas BMI derived from measured or selfreport data are ratio and subject to restriction of range when recoded. Nevertheless, it can be concluded from the present findings that various indicators of body image are related to eating disorders and SPA. Continued inquiry into the role BI has with female athlete triad variables in more heterogeneous BMI samples of athletes is especially warranted in order to provide practitioners with a more precise understanding of the nature of disordered eating correlates and possible intervention targets. A next step in understanding the triad 
Citation: Monsma EV, Gay JL, Torres-McGehee TM (2013) Physique Related Perceptions and Biological Correlates of Eating Disorder Risk among Female Collegiate Equestrians. $J$ Athl Enhancement 2:2.

in this population may be further inquiry concerning the prevalence of musculoskeletal injuries related to a decrease in bone health.

The findings in this study contribute to the evidence base by examining equestrian athletes, an understudied population, as well as including characteristics from a variety of domains. Along with these findings and because BI distortion and dissatisfaction existed in both directions, practitioners are advised to educate equestrian athletes about health-related consequences of dietary restriction and purging along with focusing on self-perception management strategies. Additionally, results from this study will aid health professionals interested in developing a practical approach for screening eating disorders and female athletes with BI dissatisfaction, along with a knowledge base for developing health risk behavior prevention programs.

\section{References}

1. Sundgot-Borgen J, Torstveit MK (2004) Prevalence of eating disorders in elite athletes is higher than in the general population. Clin J Sport Med 14: 25-32.

2. Thompson AM, Fleming KT (2007) Social physique anxiety in female varsity athletes. Advances in Psychology Research, Nova Science Publishers, NewYork, USA.

3. Malina RM, Bouchard C, Bar-Or O (2004) Growth, maturation, and physical activity, Human Kinetics, IL.

4. Diehl NS, Johnson CE, Rogers RL, Petrie TA (1998) Social physique anxiety and disordered eating: What's the connection? Addict Behav 23: 1-6.

5. Thompson AM, Chad KE (2005) Selected antecedents that place young females at risk for developing an eating disorder. In PI Swain, Adolescent Eating Disorders. Nova Science Publishers, NewYork, USA.

6. Ziegler P, Hensley S, Roepke JB, Whitaker SH, Craig BW, et al. (1998) Eating attitudes and energy intakes of female skaters. Med Sci Sports Exerc 30: $583-586$

7. Dorn LD, Dahl RE, Woodward HR, Biro F (2006) Defining the boundaries of early adolescence: A user's guide to assessing pubertal status and pubertal timing in research with adolescents. Appl Dev Sci 10: 30-56.

8. Gay JL, Monsma EV, Torres-McGehee TM (2011) Developmental and contextual risks of social physique anxiety among female athletes. Res $Q$ Exerc Sport 82: 168-177.

9. Striegel-Moore RH, McMahon RP, Biro FM, Schreiber G, Crawford PB, et al. (2001) Exploring the relationship between timing of menarche and eating disorder symptoms in black and white adolescent girls. Int J Eat Disord 30: 421-433

10. Kostanski M, Gullone E (1998) Adolescent body image dissatisfaction: Relationships with self-esteem, anxiety, and depression controlling for body mass. J Child Psychol Psychiatry 39: 255-262.

11. Frisch RE, Gotz-Welbergen AB, McArthur JW, Albright T, Witschi J, et al (1981) Delayed menarche and amenorrhea of college athletes in relation to age of onset of training. Journal of the American Medical Association 246: 1559-1563.

12. Malina RM (1998) Growth and maturation of young athletes-ls training for sport a factor? In KM Chan, LJ Micheli Sports and Children. Williams and Wilkins Asia-Pacific, Hong Kong.

13. Matina RM, Rogol AD (2011) Sport training and the growth and maturation of young athletes. Pediatr Endocrinol Rev 9: 441-455.

14. Towne B, Czerwinski SA, Demerath EW, Blangero J, Roche AF, et al. (2005) Heritability of age at menarche in girls from the Fels longitudinal study. American Journal of Physical Anthropology 128: 210-219.

15. Cash TF, Deagle EA 3rd (1997) The nature and extent of body-image disturbances in anorexia nervosa and bulimia nervosa: A meta-analysis. Int $\mathrm{J}$ Eat Disord 22: 107-125.

16. Stunkard A, Sorenson T, Schulsinger F, Kety S, Rowland LP, et al. (1983) Use of the Danish Adoption Register for the study of obesity and thinness The
Genetics of Neurological and Psychiatric Disorders. Raven Press, New York, USA.

17. Hausenblas HA, Downs DS (2001) Comparison of body image between athletes and nonathletes: A meta-analytic review. J Appl Sport Psychol 13: 323-339.

18. Hausenblas HA, Mack DE (1999) Social physique anxiety and eating disorder correlates among female athletic and nonathletic populations. J Sport Behav 22: $502-513$

19. Monsma EV, Malina RM (2004) Correlates of eating disorders risk among female figure skaters: A profile of adolescent competitors. Psychol Sport Exerc 5: $447-460$

20. Thompson AM, Chad KE (2002) The relationship of social physique anxiety to risk for developing an eating disorder in young females. J Adolesc Health 31: 183-189.

21. Monsma EV, Torres-McGehee TM, Malina RM (2011) Contextual, biological and psychological variables involved in social physique anxiety among female collegiate track and field athletes. J Sport Exerc Psychol 33: S174.

22. Furnham A, Badmin N, Sneade I (2002) Body image dissatisfaction: gender differences in eating attitudes, self-esteem, and reasons for exercise. $J$ Psychol 136: 581-596.

23. Smith AL (2004) Measurement of social physique anxiety in early adolescence. Med Sci Sports Exerc 36: 475-483.

24. Torres-McGehee TM, Monsma EV, Gay JL, Minton DM, Mady-Foster AN (2011). Prevalence of eating disorder risk and body image distortion among National Collegiate Athletic Association Division I varsity equestrian athletes. J Athl Train 46: 431-437.

25. Nichols JF, Rauh MJ, Barrack MT, Barkai HS, Pernick Y (2007) Disordered eating and menstrual irregularity in high school athletes in lean-build and nonlean-build sports. Int J Sport Nutr Exerc Metab 17: 364-377.

26. Bonci CM, Bonci LJ, Granger LR, Johnson CL, Malina RM, et al. (2008) National Athletic Trainers' Association position statement: Preventing, detecting, and managing disordered eating in athletes. J Athl Train 43: 80108.

27. Bulik CM, Wade TD, Heath AC, Martin NG, Stunkard AJ, et al. (2001) Relating body mass index to figural stimuli: population-based normative data for Caucasians. Int J Obesity 25: 1517-1524.

28. Christman SD, Bentle M, Niebauer CL (2007) Handedness differences in body image distortion and eating disorder symptomatology. Int J Eat Disord 40: 247-256.

29. Peterson M, Ellenberg D, Crossan S (2003) Body-image perceptions: Reliability of a BMI-based silhouette matching test. Am J Health Behav 27: 355-363.

30. Peterson M, Orsega-Smith E, Tholstrup L (2004) Validity of the body mass index silhouette matching test. Am J Health Behav 25: 437-443.

31. Gardner RM, Friedman BN, Jackson NA (1998) Methodological concerns when using silhouettes to measure body image. Percept Mot Skills 86: 387395.

32. Martin KA, Rejeski WJ, Leary MR, McAuley E, Bane S (1997) Is the social physique anxiety scale really multidimensional? Conceptual and statistical arguments for a unidimensional model. J Sport Exerc Psychol 19: 357-367.

33. Cronbach LJ (1951) Coefficient alpha and the internal structure of tests. Psychometrika 16: 297-334.

34. Garner DM, Olmsted MP, Bohr Y, Garfinkel PE (1982) The eating attitudes test: psychometric features and clinical correlates. Psychol Med 12: 871-878.

35. Nudelman S, Rosen JC, Leitenberg H (1988) Dissimilarities in eating attitudes, body image distortion, depression, and self-esteem between highintensity male runners and women with bulimia nervosa. Int J Eat Disord 7: 625-634.

36. Hausenblas HA, McNally KD (2004) Eating Disorder Prevalence and Symptoms for Track and Field Athletes and Nonathletes. J Appl Sport Psychol 16: 274-286.

37. Kaltiala-Heino R, Rimpelä M, Rissanen A, Rantanen P (2001) Early puberty 
Citation: Monsma EV, Gay JL, Torres-McGehee TM (2013) Physique Related Perceptions and Biological Correlates of Eating Disorder Risk among Female Collegiate Equestrians. $J$ Athl Enhancement 2:2.

and early sexual activity are associated with bulimic-type eating pathology in middle adolescence. J Adolesc Health 28: 346-352.

38. Swenne I, Belfrage E, Thurfjell B, Engström I (2005) Accuracy of reported weight and menstrual status in teenage girls with eating disorders. Int $\mathrm{J}$ Eat Disord 38: 375-379.

39. Thompson AM, Chad KE (2000) The relationship of pubertal status to body image, social physique anxiety, preoccupation with weight and nutritional status in young females. Can J Public Health 91: 207-211.

40. Stang J, Story M (2005). Guidelines for adolescent nutrition services Minneapolis, USA.

41. Casper RC, Halmi KA, Goldberg SC, Eckert ED, Davis JM (1979) Disturbances in body image estimation as related to other characteristics and outcome in anorexia nervosa. Br J Psychiatry 134: 60-66.
42. Cox LM, Lantz CD, Mayhew JL (1997) The role of social physique anxiety and other variables in predicting eating behaviors in college students. Int J Sport Nutr 7: 310-307.

43. MacKinnon DP, Krull JL, Lockwood CM (2000) Equivalence of the mediation, confounding and suppression effect. Prev Sci 1: 173-183.

44. Chan YH (2003) Biostatistics 104: Correlational analysis. Singapore Medical J 44: 614-619.

45. Gay J, Monsma EV, Torres-McGehee T (2009) Give or take a few? Comparing measured and self-reported height and weight as correlates of social physique anxiety. Res Q Exerc Sport 80: 656-662.

46. Torres-McGehee TM, Green JM, Leeper JD, Leaver-Dunn D, Richardson $\mathrm{M}$, et al. (2009) Body image, anthropometric measures, and eating-disorder prevalence in auxiliary unit members. J Athl Train 44: 418-426.

\section{Author Affiliations}

${ }^{1}$ Department of Physical Education and Athletic Training, University of South Carolina, USA

${ }^{2}$ College of Public Health, University of Georgia, Athens, USA

${ }^{3}$ Department of Physical Education and Athletic Training, University of South Carolina, USA

Submit your next manuscript and get advantages of SciTechnol submissions

* 50 Journals

* 21 Day rapid review process

* 1000 Editorial team

* 2 Million readers

* More than 5000 facebogk

* Publication immediately after acceptance

* Quality and quick editorial, review processing

Submit your next manuscript at $\bullet$ www.scitechnol.com/submission 